\title{
Role of proximal femur locking plate in management of complex proximal femoral end fractures
}

\author{
Hardip Singh Mann ${ }^{1}$, Girish Sahni2, ${ }^{2,}$, Arvind Kumar3, Anand Mohan ${ }^{4}$ \\ ${ }^{1}$ Professor, ${ }^{2}$ Associate Professor, ${ }^{3}$ Senior Resident ${ }^{4}$ Junior Resident, Dept. of Orthopaedics, Government Medical College, \\ Patiala, Punjab, India
}

*Corresponding Author:

Email: sawhneygirish@gmail.com

\begin{abstract}
Introduction: To study the role of proximal trochanteric contoured plate in management of complex proximal femur end fractures.

Materials and Methods: A total of 30 cases 11 male and 19 female patients aged 19 to 90 years [Mean age 42] were included. Time duration of surgery, total amount of blood loss, hospital stay, mobilization and weight bearing, radiological assessment of union, complications and Harris Hip score were assessed at the end of 6 months

Results: Mean duration of surgery was 72.18 mins, average blood loss was $283.75 \mathrm{ml}$, average hospital stay was 13.75 days. Mean time for radiological union was 16.8 wks and Harris hip score was 84.6. Abductor lurch occurred in 4 cases.

Conclusion: Proximal Femoral Locking Compression Plate (PFLCP) provides stable fixation for fractures of proximal end of femur especially for lateral wall fracture because it provides stable fixation of lateral fragments and prevents lateral migration of proximal fragments.
\end{abstract}

Keywords: Proximal femur fractures, Proximal femur locking plate, Harris Hip Score.

MESH words: Proximal femur fracture, Internal fixation, Extramedullary devices.

\section{Introduction}

Proximal femoral locking compression plate is developed recently that adds locking plate technique with conventional plating system. This technique could offer optimum fixation of comminuted and highly unstable fractures that are associated with more shearing and pull out forces. Proximal Femur Locking Plate provides three dimensional fixation and angular stable fixation compared with treatments already in use, even in case of unstable fracture in osteoporotic bone ${ }^{1}$. It was found to have less complications than DHS in unstale intertrochanteric fractures. ${ }^{2}$ Incidences of hardware failures are less with PFLCP. ${ }^{3}$

Failures seems related to two factors the type of internal fixation used and stability of fracture. ${ }^{4}$ The PFLCP results were good to excellent in treating unstable inter-trochanteric and sub-trochanteric fractures. We evaluated the patients on basis of duration of surgery, the amount of blood loss, hospital stay mobilization and weight bearing, radiological evaluation, complications and Harris Hip score at the end of 6 months.

\section{Materials and Methods}

This study included 30 patients with proximal femoral fractures. Informed consent was obtained from all the patients. 11 males and 19 females aged 19 to 82 years [Mean 42] were treated with proximal femoral locking plate. The mode of injury was: Road side accident [ $\mathrm{n}=12]$, and fall $[\mathrm{n}=18]$. Children and patients with compound fractures and associated head, chest and abdominal injuries were excluded. The mean interval of surgery from admission was 5 days. Preoperative skeletal or skin traction was given. Radiographs were taken; fractures were classified according to EVANS classification for intertrochanteric and SEINSHEIMERS classification for subtrochanteric fractures.

Technique: Close reduction was attempted under image intensifier before draping on traction table. We used lateral approach in all the cases. A longitudinal skin incision along the greater trochanter was given and fascia was incised. Bone was exposed through vastus lateralis muscle. Reduction was again confirmed. The plate was placed laterally along the contour of greater trochanter and temopoarily secured with K-wires. Guide wire is then inserted through proximal locking sleeve and its position is checked in AP and lateral views. After confirming the correct placement of guide wire overdrilling with cannulated drill bit was done. Three proximal locking screws of adequate length were inserted at 95, 120 and 135 degrees holes following a guide wire. The position and lenth of screws was rechecked under image intensifier in orthogonal views. The remaining distal locking screws were inserted into the shaft. Hemostasis was achieved. Wound was closed in layers under negative suction drainage.

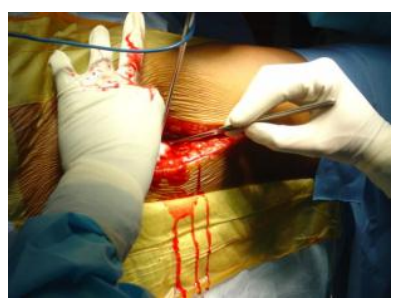

Fig. 1a: Incision 


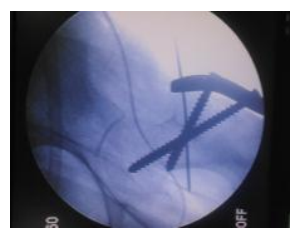

Fig. 1b: C-Arm AP View

Antibiotics and analgesics were given as per the hospital protocols. Patients were allowed to perform quadriceps exercise next day. Mobilisation with nonweight bearing was allowed, followed by partial weight bearing with walker after 6 to 8 weeks. Sutures were removed on day 14. Patients were followed up every 2 weeks for 2 months and thereafter monthly for 18 months to asses hip and knee function, limb shortening, callus growth, and growth and fixation defects

\section{Results}

Results were graded as per Harris Hip score. Out of 30 patients we achieved excellent to good results in 23 (76.66\%) patients while fair results were seen in 7 (23.33\%) patients. There were no poor results. The mean operative time was 72.19 mins in our study with average blood loss of $283.75 \mathrm{ml}$. Average duration of stay in hospital was 13.75 day. Radiological union was achieved at mean time of 16.8 weeks which was similar (16 weeks) to study done by Sun Jun et al. Complications included superficial wound infection which was seen in 3 patients and abductor lurch occurred in 4 patients. As a whole average Harris Hip score was 84.60 in Intertrochanteric and 90.50 in subtrochanteric fractures. It was also similiar to the Harris Hip results obtained by Sun jun et al (2012). On further differentiating into fracture stability pattern we found Harris Hip score to be 94.44 In unstable Intertrochanteric fractures, whereas 85 in stable Intertrochanteric fractures.

Table 1: Results as per Harris Hip score

\begin{tabular}{|l|c|c|}
\hline \multirow{2}{*}{ Results } & \multicolumn{2}{|c|}{ PFLP } \\
\cline { 2 - 3 } & No. of cases & \% age \\
\hline Excellent & 6 & 20 \\
\hline Good & 17 & 56.66 \\
\hline Fair & 7 & 23.34 \\
\hline Poor & 0 & 0 \\
\hline Total & $\mathbf{3 0}$ & $\mathbf{1 0 0}$ \\
\hline
\end{tabular}

\section{Case 1}

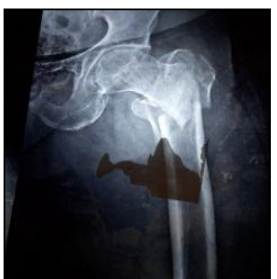

Fig. 2a: Pre operative

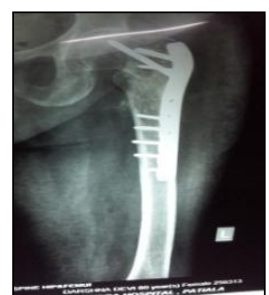

Fig. 2b: X-ray showing union

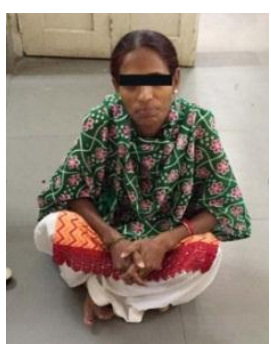

Fig. 3: Patient sitting cross legged

Case 2

Fig. 4a: Post-op AP
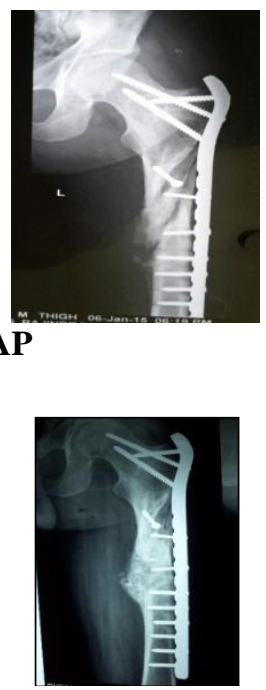

Fig. 4b: X-ray showing union

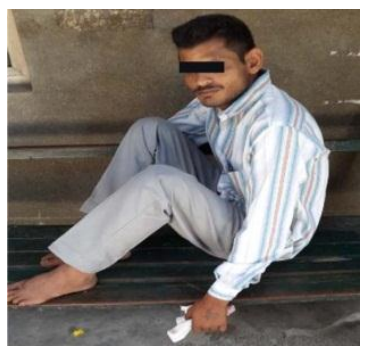

Fig. 5: Follow-up sitting with hip flexed

\section{Discussion}

Proximal femur fractures are seen with increasing frequency and severity as life expectancy in the population increases. Primary goal of treatment in an elderly patient with proximal femur fracture is the return the patient to his pre fracture functional stage and activity as early as possible. Rapid mobilization of 
these patients reduces the mortality and morbidity rate in these patients.

Before the advent of suitable fixation devices, treatment of proximal femur fractures was nonoperative, consisting of prolonged bed rest in traction. This method was associated with high complication rates, such as; decubitus ulcer, pressure sores, urinary tract infection, joint contractures, pulmonary and thromboembolic complications, resulting in a high mortality rate. In addition, fracture healing was accompanied by varus deformity and shortening. For these reasons, treatment of proximal femur fractures by internal fixation became the method of choice. The same can be achieve with various fixation methods including Dynamic hip screw [DHS], Dynamic condylar screw [DCS], angle blade plate, and proximal femur locking plate [PFLP]. It is still not unequivocal about use of these methods in particular type of fracture pattern and in which age group and bone condition which implant is better than the other. The present study was conducted to study the role of PFLCP in proximal end fractures of femur. adults but the mean age differed in few depending upon the number of the fractures studied. The patients in our study ranged in age from 19 to 90 years. Mean age was $42.45 \mathrm{yrs}$ in our study. Mean age was 79 year in study by bolhofner, ${ }^{5} 51$ year in the study by Gupta et al ${ }^{6}$ and it was 51.4 year in study by Ravi et al. ${ }^{7}$ Females [55\%] were found to be a little higher than males [45\%]. This was similar to study done by Kulkarni et $\mathrm{al}^{8}$ which had $76 \%$ females and $26 \%$ males. Dhamanganokar et al [2013] $]^{9}$ had 29 female and 11 male and 112 female and 82 males in study by Parker et al ${ }^{10}$ which suggested that incidence of proximal femoral fractures was higher in females. This sex pattern of involvement shows that fracture of proximal femur was more in females which may be due to post. menopausal osteopenia and related factors.

It was found during the course of study that commonest cause of proximal end femur fracture was fall $75 \%$ of patients] while $25 \%$ cases were due to road side accidents.this was in accordance with study done by Hornby et al $(2015)^{11} 55 \%$, Gupta $^{6}$ et al (1974) $79.4 \%$.

In this study $77.77 \%$ of fractures were intertrochanteric fractures; of which $55.55 \%$ were stable and $22.22 \%$ were unstable.Stability of fractures was based on the integrity of posteromedial cortex in accordance with Evans classification. Fractures with stable.Posteromedial cortex constitutes mainly the lesser trochanter. ${ }^{12-16}$

Operative time in our study was between 6090mins (mean 72.18mins). The operative time for PFLP was 80 mins in study of Kumar et al (2014) ${ }^{17}$ and it was 62.46 mins in study of Han et $\mathrm{al}^{18}(2012)$
Extracapsular fractures of femur occur mainly in intact posteromedial cortex were considered as

Blood loss was between 250-350 ml (mean $283.75 \mathrm{ml})$, whereas in study of Kumar et a $1(2014)^{17}$ it was 200ml; and in Damanganokar ${ }^{9}$ (2013) it was $286 \mathrm{ml}$. Drain output was less than $100 \mathrm{ml}$.

Partial weight bearing was started if features of instability were not there at 4 weeks. $93.34 \%$ patients started partial weight bearing at 6 weeks. Full weight bearing was started in most patients $(70 \%)$ at 14 weeks. $49.8 \%$ of patients showed radiological union at around 17 weeks.

The time of radiological union in study of Pneugonda et al $(2015)^{19}$ was 15.5 weeks while in dhamanganokar et al (2013), it was 16.5 weeks, 13.5 weeks in Kumar et al and 17 weeks in study by Vanamali et al. ${ }^{1}$ And it was found to be lesser than DHS in study by Zhong et al. ${ }^{20}$

In present study $83.34 \%$ of patients were discharged within 15 days of surgery. The average hospital stay in study of Dhamanganokar ${ }^{9}$ et al (2013), it was 18 days.

Harris Hip score in stable IT fracture was 77.4 while in unstable fractures it was more i.e. 85. Similarly in subtrochanteric fractures, it was 90.5. This scoring shows that PFLCP is a better implant option in unstable proximal femoral and subtrochanteric fractures.

Regarding complications in our study $17.64 \%$ patients developed superficial infections, $23.54 \%$ patients had abductor lurch, $11.76 \%$ patients suffered from delayed union and hip pain.17.64\% patients walked with limp. In study of Dhamanganokar et al (2013), deep wound infection occurred in 3 patients, varus collapse occurred in 2 patients and implant cut out occurred in 1 patient. Sun-jun et al (2012) ${ }^{21}$ found superficial wound infection in 3 patients, two patients developed implant failure ${ }^{21}$ due to early weight bearing and underwent surgery again.

\section{Conclusion}

The Proximal Femur Locking Compression Plate (PFLCP) is a kind of stable and effective internal fixation for treating proximal femoral end fractures which has the advantage of stable fixation especially for the lateral femoral wall fracture. The PFLCP can be a better alternative for the treatment of unstable proximal femoral end fractures because it provides stable fixation of the lateral fragments and prevents the lateral migration of proximal fragments. It also provides early mobilization of patients and allow them early return to activities of daily living.

Table 2: Post-operative complications

\begin{tabular}{|l|c|c|}
\hline \multirow{2}{*}{ Complications } & \multicolumn{2}{|c|}{ PFLP } \\
\cline { 2 - 3 } $\begin{array}{l}\text { Superficial } \\
\text { Infections }\end{array}$ & No. of Cases & \% age \\
\hline Limp & 3 & 17.64 \\
\hline Abductor lurch & 4 & 17.64 \\
\hline Hip Stiffness & 3 & 23.52 \\
\hline
\end{tabular}

Indian Journal of Orthopaedics Surgery, January-March,2018;4(1):65-68 


\begin{tabular}{|l|l|l|}
\hline Delayed Union & 2 & 11.76 \\
\hline Hip Pain & 2 & 11.76 \\
\hline
\end{tabular}

Table 3: Time of radiological union

\begin{tabular}{|l|c|c|}
\hline \multirow{2}{*}{$\begin{array}{l}\text { Time } \\
\text { in weeks) }\end{array}$} & \multicolumn{2}{|c|}{ PFLP } \\
\cline { 2 - 3 } & No. of Cases & \% age \\
\hline 14 & 4 & 13.34 \\
\hline 16 & 11 & 36.66 \\
\hline 18 & 13 & 43.34 \\
\hline 20 & 2 & 6.66 \\
\hline Total & $\mathbf{3 0}$ & $\mathbf{1 0 0}$ \\
\hline
\end{tabular}

\section{References}

1. Vanamali B. et al. A comparative study of clinicoradiological outcome: DHS verses PFLCP in intertrochantric fractures of femur. Journal of evidence based medicine and healthcare. 2015 Month: November Volume: 2 Issue: 50 Page:8565-8570.

2. Zhong B et al. A comparison of proximal femoral locking compression plates with dynamic hip screws in extra capsular femoral fractures. OrthopTraumatolSurg Res. 2014 Oct;100(6):663-8. doi: 1016/j.otsr.2014.06.012. Epub 2014 Aug 22.

3. Simpson AH, Varty K, Dodd CA. Sliding hip screws: modes of failure. Injury. 1989;20:227-231.

4. Tencer AF, Johnson KD, Johnson DWC, Gill K. A biomechanical comparison of various methods of stabilisation of subtrochanteric fractures of the femur. $\mathbf{J}$ Orthop Res. 1984;2:297:181.

5. Bolhofner BR, Russo PR, Carmen B. Results of intertrochanteric femur fractures treated with a 135degree sliding screw with a two hole side plate. J Orthop Trauma. 1999;13(1):5-8.

6. Gupta RC. Conservative treatment of intertrochanteric fracture of femur. Indian Journal of Orthopaedics 1974; 36(6):229.

7. Ravi G.O., Shaik H S. Study of proximal femoral locking compression plate in extra capsular fracture neck of femur.International Journal of Research in Medical Sciences. Int J Res Med Sci. 2015 Dec;3(12):3726-3733.

8. Kulkarni GS. Treatment of intertrochanteric fracture of hip by modified Richards's compression and collapsing screw. Indian Journal of Orthopaedics 1984:18(1):30-34.

9. Dhamangaonkar AC, Joshi D, Goregaonkar AB, Tawari AA. Proximal femoral locking plate versus dynamic hipscrew for unstable intertrochanteric femoral fractures. J Orthop Surg (Hong Kong). 2013;21(3):317-22.

10. Parker MJ. Trochanteric hip fracture. Acta Ortho Scand 1996; 67(4):329-332.

11. Hornby R, Evans JG, Vardon V. Operative orconservative treatment for trochanteric fractures of thefemur. A randomised epidemiological trial in elderlypatients. J Bone Joint Surg Br. 1989;71(4):619623.

12. Sadowski CAL, Saudan M, Riand N, Stern R, Hoffmeyer $\mathrm{P}$. Treatment of reverse oblique and transverse intertrochanteric fractures with use of an intramedullary nail or a $95^{\circ}$ Screw-Plate: A Prospective, Randomized Study. J Bone Joint Surg Amrt 2002; 84:372-81.

13. Gadegone WM and Salphale YS. Short proximal femoral nail fixation for trochanteric fractures. Journal of Orthopaedic Surgery 2010; 18(1):39-44.

14. Simmermacher RK, Bosch AM, Van der Werken C. The AO/ASIF- proximal femoral nail (PFN): A new device for the treatment of unstable proximal femoral fractures. Injury 1999;30:327-32.

15. Tencer AF, Johnson KD, Johnson DWC, Gill K. A biomechanical comparison of various methods of stabilisation of subtrochanteric fractures of the femur. $\mathbf{J}$ Orthop Res. 1984; 2:297:181.

16. Windoff J, Hollander DA, Hakmi M, Linhart W. Pitfalls \& complications in the use of proximal femoral nail. Lagenbecks Arch Surg. 2005;3901.

17. Kumar N, Kataria H, Yadav C, Gadagoli BS, Raj R.Evaluation of proximal femoral locking plate in unstableextracapsular proximal femoral fractures: Surgicaltechnique \& midterm follow up results. J Clin Orthop Trauma. 2014;5(3):137-145.

18. Han GH, Wei W, Gu J. Comparison of proximal femorallocking plate and Gamma nail in the treatment of thefemoral intertrochanteric fractures in the elder. Zhongguo Gu Shang. 2012;25(10):796-9.

19. Penugonda RS, Vanga A, Babu GRS, Sagar SRV.Comparative study between proximal femoral nailing anddynamic Hip screw in the Management of Intertrochanteric fractures of Femur. Journal of Evidencebased Medicine and Healthcare 2015;(2)5:541548.

20. Zhong B et al. A comparison of proximal femoral locking compression plates with dynamic hip screws in extra capsular femoral fractures. Orthop Traumatol Surg Res. 2014 Oct;100(6):663-8. doi: 10.1016/j.otsr.2014.06.012. Epub 2014 Aug 22.

21. Sun-Jun Hu, Zhang S, Guangrong YU. The treatment of femoral subtrochanteric fractures with the proximal lateral femur locking plates. Acta Ortop Bras.2012;20(6):329- 33 . 